\title{
Possible way of bronchial asthma treatment through the effects of acupuncture point $\mathrm{Li} 4$
}

\author{
Dorko František, Durdaková Radka* and Durdák Radomír \\ Department of Anatomy, Faculty of Medicine, University of Ostrava, Syllabova 19, Czech Republic
}

\begin{abstract}
Our study focuses on the large intestine meridian, which contains 20 acupuncture points and it is located in the upper part of the body. Besides its effects on the digestive tract this pathway also has beneficial effects in treatment of respiratory diseases, including chronic diseases. According to authorities is the beneficial effect of this pathway described in treatment of bronchial asthma, more precisely by the point LI4, on which we will focus in this correlation.
\end{abstract}

\section{Introduction}

Acupuncture is a part of the traditional Chinese medicine (also known as the Eastern medicine), and it's believed to be its eldest part. It's age is supported by findings of stone and bone needles older than 7 thousand years, or finding s of bronze needles. Probably people began to practice it as the main treatment method under the ruler Fu-siho, who ruled in the period of 3 thousand years B.C. and who presumably designed 9 different types of needles for acupuncture practice. During the year 1027 were created first unique bronze statues of a male and female for acupuncture training - they contained all then known points in total number of 657 and in each was a hole filled with a colored liquid sealed by wax. As a result of this could be in year 1027 founded first medical schools in China focused on teaching of acupuncture, whereas until then was knowledge necessary for it's practicing and experiences passed on from father to son. [1]

The essence of treatment using acupuncture is the insertion of specially purposed needles into acupuncture points on the human body. The axes connecting these points are called meridians and are according to ancient teaching considered to be channels through which flows energy, in Chinese called qi (čchi). The traditional Chinese acupuncture described 365 active points, but throughout the years their number increased to approximately 1000 - only about 200 are currently used in the medical practice. The 2 central pathways contain 361 acupuncture points and 12 organ meridians, which are in pairs (symmetrically run on both left and right side of the body) [2].

Our work is targeted at the large intestine meridian, which contains 20 points. The pathway is used not just for acupuncture treatment of illnesses related directly to the passage of the pathway and digestive system affections, but also in treatment of allergies, respiratory system problems as well as chronic respiratory diseases [3]. Our study focuses on the $4^{\text {th }}$ acupuncture point of this pathway, Hegu, which is besides other used also in treatment of bronchial asthma [4]. We have elaborated the possible effect of acupuncture on bronchial asthma in our previous more detailed study [5]. which proved a positive effect of irritation of LU5 in treatment of bronchial asthma (Figure 1).

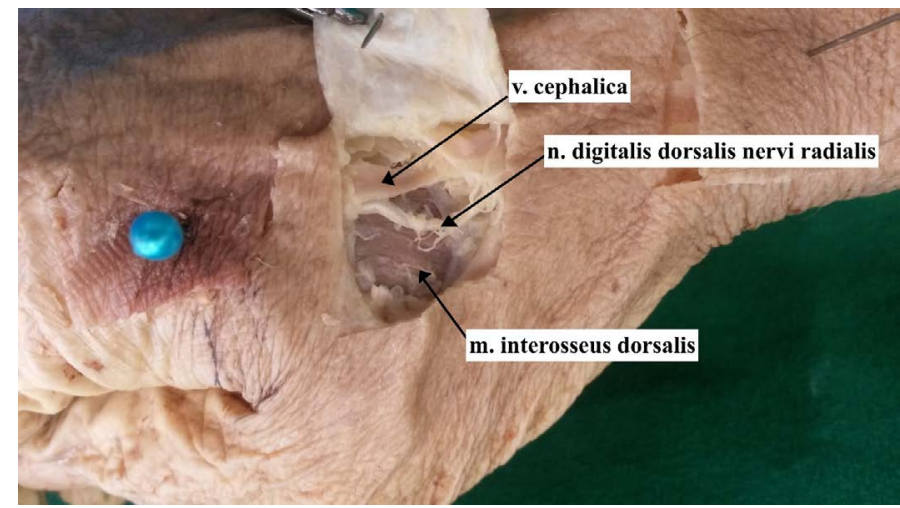

Figure 1: Acupunture point

\section{Material and methods}

Our study is comprised of multiple phases so that individual points of research are subjected to as low deviation and error rate as possible.

In the initial section we have closely studied the acupuncture pathway for our research, in this case the LI (IC) - the large intestine. The pathway begins on the thumb side of the hand and continues on its dorsal side between tendons of $\mathrm{m}$. extensor pollicis longus and $\mathrm{m}$. extensor pollicis brevis. After the passage on the forearm it continues through the outer angle of the elbow to the shoulder, where it in the highest point circles around the acromion and through fossa supraclavicularis follows its deep passage, the superficial passage can be seen on the face through two acupuncture points of this pathway [6].

*Correspondence to: Durd’aková Radka, Department of Anatomy, Faculty of Medicine, University of Ostrava, Syllabova 19, Czech Republic, E-mail: radka.durdakova@gmail.com

Key words: bronchial asthma, acupuncture, cadaver, large intestine meridian, qi, autonomous nervous system, the sympathetic nervous system

Received: June 05, 2018; Accepted: June 11, 2018; Published: June 18, 2018 
The individual points of the large intestine meridian were thoroughly studied from international literature and also using traditional Chinese drawings and models for practicing of acupuncture for healers. Special sound mats were used for training of the insertion of the needle and in the end selected points were tried on ourselves in order to verify or rule out the passage of a nerve in the proximity of the insertion, described as the feeling of "qi“" (čchi).

After fulfilment of all these experiences were in the second phase projected points of the large intestine meridian on a live model (since during the fixation proces it's not always possible to guarantee a neutral position of the cadaver) and thereafter onto cadavers as well as on individual upper limbs - this was done in order to improve verification by extending the possible structural deviations of the human body (passage of nerves, veins, etc..). The dissection included also an area around the point, as it is not possible to verify the feeling of qi on a cadaver, and also small deformations and tissue dehydration occur in the cadaver after its stabilization and fixation during the fixation process, which leads to a change in the physical nature of the human body. After determination of the individual points and verification by the physician was allowed to proceed with the dissection of particular areas surrounding points, where we proceeded using the "window" method", thanks to which it's possible to further work with points after the dissection and its possible to study individual layers of structures which go through them. Tissues were separated with regard to the passing of all particular structures and their layers. After finishing of the dissection were points photo documented and described. No seevere differences in psrticular structures were found in thr points [7-11].

\section{Results}

In the location of acupuncture point LI4, in Chinese Hegu, were during the dissection found the following structures: musculus interosseus dorsalis, vena cephalica and nervus digitalis dorsalis nervi radialis $[8,9]$. During the application of acupuncture needle and finding of effective puncture point the physitian is trying to achieve a so called feeling of qi during the insertion of needle [1-3]. This state is described as itching or tingling spreading along the limb, based on which it can be concluded that the main affected structure is the nerve, when its irritation or irrittaion in its close proximity invokes the so called qi. As it was stated before, in the area of LI4 is the only nervous structure the nervus digitalis dorsalis nervi radialis. This nerve is created by branching from the radial neve, which has root innervation in $\mathrm{C} 5-\mathrm{C} 8$, in som literature is mentioned also the $\mathrm{Th} 1$, and leaves the spinal collumn through the lateral fascicle. The radial nerve enters after its descend behind the axillar artery into the sulcus nervi radialis, which is located on the humerus, and moves to the radial side from before ulnar side. It gets on the frontal side through the septum intermusculare brachii laterale and in the septum at the elbow level it branches into ramus superficialis a profundus. Ramus superficialis nervi radialis is a sensitive nerve, which passes along the forearm together with the radial artery and under tendo musculi brachioradialis rotates around the radius and gets on the dorsal side of the hand, where it sends rami communicans ulnaris and nervi digitales dorsales $[8,9]$. The passage of the spreading nervous impulse caused by the insertion of an acupuncture needle close to the nerve is therefore according to performed dissections probably spreading along the nerves through nervus radialis up to the root inervation $\mathrm{C} 5-\mathrm{C} 7$, where is in the section C5 located sympathetic ganglion cervicale medium, which sends postganglionic fibers, the rami communicantes grisei, into serves of $\mathrm{C} 4$ and $\mathrm{C} 5$ and preganglionic fibers are entering the ganglion cervicale medius through the truncus symathicus from the area of connection of cervical and thoracic spine. Through sympathetic betal receptors and through irritation of postganglionic fibres occurs inhibition of mucous secretion in bronchi.

\section{Discussion}

Results of the study of LI4 proves also our previous study [5] when even though that they are different accupuncture points belonging to different nervous pathways, which belong under different fascicles (LU5 through nervus musculocutaneous from the lateral fascicle with root innervation C5-C7 and LI4 through the radial nerve from the fasciculus posterior with root innervation from C5-C8), we are finding the final connection in the area of $\mathrm{C} 5$, where their pathway probably connects, and both therefore cause activation of bronchial dilatation and inhibition of secretion through Beta 1 receptors.

Both these points, the LU5 and LI4, are according to knowledge of healers practicing acupuncture described as points in clinical practice positively affecting the bronchial asthma [12-15], and therefore the unison of the pathway of irritation caused by the insertion of an acupuncture needle into point LI4 in the proximity of the nerve nervus digitalis dorsalis nervi radialis with the before described pathway proves this theory.

Our theory of effect of the nerve impulse is moreover supported also by the fact that in clinical practice are commonly used drugs that cause bronchial dilatation to achieve a relief from asthmatic attack.

An impulse caused by the irritation of a vein, inflamation or other therories of acupuncture effects may undubitably have a role as well [16-20]. More authors have already focused on the efect of acupuncture on the bronchial asthma, and most of them have already proven its positive effect [16-30].

\section{Conclusion}

Based on our study we support the hzpothesis that the major role in the effect of acupuncture treatment in bronchial asthma is conveyed by the autonomous nervous system and that applies in both acupuncture points LU5 and LI4.

We have proven the passage of nervus digitalis dorsalis nervi radialis through the acupuncture point LI4. The nervus digitalis dorsalis nervi radialis branches from the nervus radialis, which has root innervation in the 5th -8 th cervical segment. A probable way of spreading of the impulse, which was caused by the insertion of an acupuncture needle in the proximity of nervus digitalis dorsalis nervi radialis is in case of correct application spreading of impulse into sympathetic rami communicantes grisei, which subsequently through betal receptors cause bronchial dilatation and lowering of bronchial secretion, which leads to imrpovement of symptoms of bronchial asthma and relief to the patient, which supports our hypothetis.

\section{Acknowledgment}

This work was financed from SGS 05/LF/2017

\section{Disclosure statement}

The authors declare that they have no conflicts of interest and no financial interests related to the material of this manuscript.

\section{References}

1. Unschuld PU, Huang DW (2003) Nature, Knowledge, Imagery in an Ancient Chinese Medical Text. Berkeley and Los Angeles, California University of California Press 
2. Šmirala J (2005) Compendium of Acupuncture. Martin: Osveta p. 447th.

3. Hecker HU (2010) Pocket textbook Acupuncture: Body Points, Ear and startup. Prague: Grada p: 285.

4. Joos ME, $\mathrm{Zu} \mathrm{H}$ (1997) Acupuncture in the treatment of bronchial asthma. In: MaricOehler W, Hunten K eds. 1st Mainz Acupuncture Symposium, Acupuncture and University. Stuttgart: Hippocrates pp:72-83.

5. Dorko F, Durdáková R, Durdák R (2017) Anatomical study of potential connection between the acupuncture point LU5 and sympathetic reaction of spinal nerves. $J$ Med Med Sci 5: 187-191.

6. Wong YM (2013) An understanding of anatomy under the LI4 acupuncture point. Acupunct Med 31: 333. [Crossref]

7. Kessler J, Streitberger K (2008) Perforation of the median nerve with an acupuncture needle guided by ultrasound. Acupunct Med 26: 231-233. [Crossref]

8. Cihák R (2004) Anatomy 2 modified and supplemented edition Prague

9. Netter FH (2012) Atlas of Human Anatomy. 2nd ed. Prague: CPress p: 131-2.

10. Kim J, Oh HJ, Yoon SP (2015) A cadaveric study of needle insertion at LI11. Acupunct Med 33: 497-499. [Crossref]

11. Joo Oh H, Ko YK, Cho SS, Yoon SP (2012) A cadaveric study of needle insertion at PC6 in eight wrists of four subjects and an understanding of the anatomy. Acupunct Med 30: 44-46. [Crossref]

12. White A (2004) A cumulative review of the range and incidence of significant adverse events associated with acupuncture. Acupunct Med 22:122-33.

13. Scheewe S, Vogt L, Minakawa S, Eichmann D, Welle S, et al. (2011) Acupuncture in children and adolescents with bronchial asthma: a randomised controlled study. Complement Ther Med 19: 239-46.

14. Creer TL, Wigal JK, Kotses H, Hatala JC, McConnaughy K, et al. (1993) A life activities questionnaire for childhood asthma. J Asthma 30: 467-473. [Crossref]

15. Martin J, Donaldson AN, Villarroel R. Parmar MK, Ernst E, et al. (2002) Efficacy of acupuncture in asthma: systematic review and meta-analysis of published data from 11 randomised controlled trials. Eur. Respir.J 4: 846-52.

16. Medici TC, Grebski E, Wu J, Hinz G, Wüthrich B (2002) Acupuncture and bronchial asthma: a long-term randomized study of the effects of real versus sham acupuncture compared to controls in patients with bronchial asthma. J Altern Complement Med 8: 737-750. [Crossref]
17. Chow OK, So SY, Lam WK, Yu DY, Yeung CY (1983) Effect of acupuncture on exercise-induced asthma. Lung 161: 321-326. [Crossref]

18. Fung KP, Chow OK, So SY (1986) Attenuation of exercise-induced asthma by acupuncture. Lancet 2: 1419-1422. [Crossref]

19. Sato M, Katsumoto H, Kawamura K, Sugiyama H, Takahashi T (2003) Peroneal nerve palsy following acupuncture treatment. A case report. J Bone Joint Surg Am 85-85A: 916-8. [Crossref]

20. Zhao LJ (2015) Acupuncture Meridian of Traditional Chinese Medical Science: An Auxiliary Respiratory System. Acupunct Meridian Stud 8: 209-215.

21. Gruber W, Eber E, Malle SD, Pfleger A, Weinhandl E, et al. (2002) Laser acupuncture in children and adolescents with exercise induced asthma. Thorax 57: 222-225. [Crossref]

22. Ng DK, Chow PY, Ming SP, Hong SH, Lau S, et al. (2004) A double-blind, randomized, placebo-controlled trial of acupuncture for the treatment of childhood persistent allergic rhinitis. Pediatrics 114: 1242-1247. [Crossref]

23. Wen MC, Wei CH, Hu ZQ, Srivastava K, Ko J, et al. (2005) Efficacy and tolerability of anti-asthma herbal medicine intervention in adult patients with moderate-severe allergic asthma. J Allergy Clin Immunol 116: 517-524. [Crossref]

24. Christensen PA, Laursen LC, Taudorf E, Sørensen SC, Weeke B (1984) Acupuncture and bronchial asthma. Allergy 39: 379-385. [Crossref]

25. Dias PLR, Subramaniam S, Lionel ND (1982) Effects of acupuncture in bronchial asthma: preliminary communication. $J R$ Soc Med 4: 245-248.

26. Tandon MK, Soh PF, Wood AT (1991) Acupuncture for bronchial asthma? A doubleblind crossover study. Med J Aust 154: 409-412. [Crossref]

27. Linde K, Jobst K, Panton J (2000) Acupuncture for chronic asthma. Cochrane Database Syst Rev 2: 000008.

28. Virsik K (1980) The effect of acupuncture on pulmonary function in bronchial asthma." Asthma. Karger Publishers 14: 271-275.

29. Zang J (1990)Immediate antiasthmatic effect of acupuncture in 192 cases of bronchial asthma. $J$ Tradit Chin Med 10: 89-93. [Crossref]

30. Jiao Y (2016) Explanation of Evidence-based Guidelines of Clinical Practice with Acupuncture and Moxibustion: Adult Bronchial Asthma Zhongguo Zhen Jiu 36: 529531. [Crossref]

Copyright: (C2018 František D. This is an open-access article distributed under the terms of the Creative Commons Attribution License, which permits unrestricted use, distribution, and reproduction in any medium, provided the original author and source are credited. 